\title{
Selection of a Multi-Functional Controller for the Software and Hardware Complex of an Automated Control System for a Thermal Power Plant
}

\author{
Valeria Dmitrieva ${ }^{1}$, Pavel Sizin², ${ }^{2}$, and Ilyas Avkhadiev ${ }^{1}$ \\ ${ }^{1}$ Gubkin University, 119991, Moscow, Leninsky prospect, 65, Russia \\ ${ }^{2}$ NUST MISiS, 119049, Moscow, Leninsky prospect, 6, Russia
}

\begin{abstract}
The article describes the main tasks that need to be solved when automating technological processes at TPS. Technological processes at TPS take place in difficult conditions, which complicates the management tasks. When creating an automated control system, modern software and technical complexes are used, which are developed by domestic manufacturers. The software and hardware complex allows you to solve all the problems of monitoring and controlling technological processes in all operating modes of power equipment. They can be used for both newly constructed and reconstructed energy facilities. The basis of the Software and hardware complex is programmable logic controllers that support medium and distributed automation. The article discusses some Russianmade controllers. Since 2019, the automated control system of the boilereconomizer is being designed by NVT-Systems at the Dzerzhinsk TPS. The implemented Software and hardware complex needs to be integrated into the existing automation structure, in addition, simplicity, reliability and redundancy are required. For these reasons, the REGUL500 controller was selected. The controller is characterized by very high performance, reliability, and the ability to work in distributed systems in real time. In addition, the advantages of the REGUL500 controllers are: high accuracy of the measuring channels; the possibility of hot-swapping modules of all types; resistance to external influences. The REGUL controller has a set of various Russian certificates of conformity.
\end{abstract}

\section{Introduction. Automation of technological processes at a thermal power plant}

The production of heat and electricity directly depends on the process of extracting energy resources (coal, fuel oil, gas). Extraction of minerals from the subsoil is not possible without energy consumption [1]. All production and technological processes in this area are interconnected. The resulting waste from the operation of thermal power plants requires disposal $[2,3]$. Disposal and processing of industrial waste requires additional energy and

\footnotetext{
*Corresponding author: mstranger@list.ru
} 
financial costs. The use of man-made waste in a closed cycle of the main and auxiliary production in the extraction and use of minerals in the energy sector is seen as the most effective way of the disposal $[4,5]$.

For the uninterrupted functioning of the entire production cycle, a clear, automated quality control of the incoming minerals [6], power quality control [7] and the distribution of energy flows are required.

Large thermal power plants (TPS) form the basis of modern energy. Labor-intensive technological processes associated with the production and distribution of heat and electrical energy at modern TPS are mainly mechanized, and the operator's task is to control mechanisms and installations and observe their work directly or using control and measuring instruments [8]. However, even the complete mechanization of twenty-four-hour power units does not relieve the operator of the need to control the main and auxiliary equipment. This led to the active development of automation in the power industry [9]. When automating heat and power equipment with the help of control systems, the following tasks are solved: automatic control of the current values of the technological process parameters; automatic protection and signaling about the state of the main and auxiliary equipment; remote control of machines and mechanisms; automatic continuous regulation of technological parameters of the process; automatic discrete switching on or off of regulators, machines, mechanisms and installations in the required sequence [10]. Listed functions are performed by control subsystems. These subsystems formcomplex APCS.

Local automatic control systems carry out continuous and sufficiently high-quality control of individual technological processes. Technological processes at the TPS take place in difficult conditions, which are characterized by the continuity of consumption and the impossibility of storing finished products; fast flow of processes in the turbine generator and large delays along the main channels of control actions in the steam boiler; constant risk of severe accidents due to high steam parameters and flue gas temperatures, etc. All this complicates the tasks of managing TPS. The start-up and shutdown processes of power units have become much more complicated. They involve many monitoring and control operations that must be carried out simultaneously on a steam boiler and a turbine, and in a strict sequence.

In connection with the transition to the block layout of power equipment, the requirements for automated control systems have changed significantly [9]. The number of simultaneously monitored parameters has increased many times, the reporting forms have become more complicated, and the responsibility of measurements for the most important parameters has increased. At the block TPS, it became necessary to radically change the management as a whole on the basis of the unity of the technological process in power units. It was necessary, using a single set of technical means, to focus on solving the main control task: fulfilling a given electric load schedule and minimizing energy losses. Modern software and hardware complexes are a complex of microprocessor-based automation equipment, which includes microprocessor controllers, communication devices with an object, operator display panels and servers for various purposes, industrial networks that allow connecting the listed components.

They are intended to create distributed control systems for technological processes with various information capabilities. Currently, the market for domestic microcontrollers is represented by a number of manufacturers: «Прософт-Системы», «Овен», «Текон», «Треи», «НВТ-Автоматика». The task of the authors is to review and analyze the functional capabilities of domestic controllers that are of interest for their use in software and hardware complexes for the automation of heat and power facilities.

One of the main tasks of process control at a TPS is to maintain a continuous correspondence between the amounts of generated and consumed energy [11 - 13]. 
The block layout of equipment and the specific features of the operation of block installations (participation in covering irregularities in the electric load schedule, frequent starts and stops of power units, etc.) have complicated the tasks of managing the TPS.

Achievement of the main goal of power unit control with the simultaneous performance of their functions by the automated control subsystems of the boiler unit, turbine and generator is associated with the introduction of a unified automated process control system at thermal power plants, designed to generate and implement control actions in accordance with the accepted control criteria $[14,15]$.

\section{Software and hardware complexes for automation of technological processes}

Modern software and hardware complexes are built in accordance with world achievements in the field of network architecture, reliability and highly efficient human-machine interface. They allow solving all problems of monitoring and control of technological processes in all modes of operation of power equipment and processes (start-up, shutdown, normal operation), which is achieved due to a high level of process automation [16].

These software and hardware complexes can be used to create automated control systems for technological processes for both newly built and reconstructed energy facilities. The technical capabilities of software and hardware systems are optimal both for large control systems, the number of signals in which is measured in many thousands, and for small systems with several tens or hundreds of signals. Hardware and software tools ensure compatibility with both domestic and foreign peripheral equipment, are easily combined with all types of sensors, valves, valves, dampers, pumps, smoke exhausters, fans and other actuators.

The scope of work on the creation and implementation of automated control systems for technological processes based on the specified software and hardware complexes includes the preparation of initial data, design, manufacture, installation, adjustment, commissioning, warranty and post-warranty service, personnel training [17, 18].

In production, automated control systems for technological processes are usually performed in three levels [19].

The lower level (field level) represents various sensors and actuators (motors, control valves, dampers, pumps, etc.).

Middle level - The controller level consists of programmable logic controllers. It receives field data and issues control commands to the lower level. Control in programmable logic controllers is carried out according to a previously developed algorithm, executed cyclically: data reception - processing - issuance of control commands.

The top level is the level of visualization, dispatching and data collection. At this level, a person, an operator (dispatcher) is involved. If an operator controls a distributed system of machines, mechanisms and units, then for such dispatching systems the term SCADA (Supervisory Control And Data Acqusition) is often used. The upper level of the APCS provides collection and archiving of the most important data from programmable logic controllers, their visualization, i.e. .e. visual representation in the form of mnemonic diagrams, possibly animated. Mnemonic diagrams reflect the flow and parameters of the technological process on the screen.

Upon receipt of data, the system compares them with the settings and, when the permissible limits are exceeded, notifies the operator using an alarm. The operator, who must be authorized to start work, starts the technological process, and then has the ability to stop it in whole or in part, can change the operating modes of the units, changing the setpoints, etc. In this case, the system registers the course of the technological process, including the actions of the operator. 
The subsystems of the automated control system for technological processes of a TPS are critical to the response time to various process events; they are real-time systems (RT). It is unacceptable for them to be late in issuing a control message, since this is fraught with an accident.

In "NVT-Systems", where one of the authors of the article works, they develop and implement automated control systems for technological installations, blocks and processes at TPS. For this purpose, a multiplatform intelligent distributed standard system (MIRTS) [20] was created, which is a combination of software and hardware based on standard information exchange protocols. Both software and hardware were developed by leading domestic manufacturers. The use of Russian-made controllers and domestic Softlogic and SCADA systems in MIRTS makes MIRTS a good means of import substitution.

MIRTS is designed to create fully functional automated control systems for technological processes, large-scale automated dispatch control systems, and integrated metering systems for energy and industrial facilities. Automated systems created with the help of MIRTS have a classic multi-level structure described above.

MIRTS is used to work with distributed network structures. Its components are compatible and can be used in various combinations. Automated control systems for technological processes created on the basis of MIRTS have high reliability, speed and the ability to implement complex control algorithms.

MIRTS includes several families of modern controllers from Russian manufacturers; a set of compatible SoftLogic and SCADA systems; standard control cabinets that provide the ability to effectively place network controllers near control objects; standard solutions for the development of modern automated workstations and control panels based on standard personal computers, servers, overview screens.

The structure of MIRTS is shown in Figure 1.

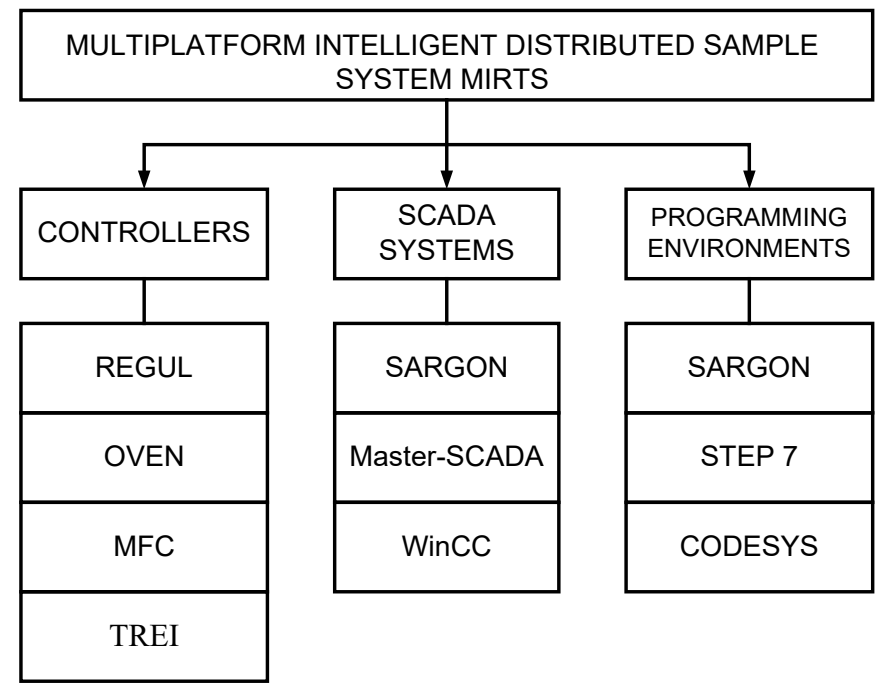

Fig. 1. Structure of the MIRTS multiplatform system

MIRTS tools allow you to efficiently create fully functional automated control systems for complex heat and power facilities of power plants of various sizes (installations, power units, workshops, stations, production facilities) and their equipment. These automated control systems are connected to relay protection and automation systems. Due to the versatility of the principles of construction of automated control systems for technological processes used in MIRTS, they are successfully applied in many industries: energy, petrochemistry, nuclear industry, metallurgy, fiberglass production, etc. 
The MIRTS system performs information, control and auxiliary service functions in automatic and automated modes. When performing functions, special attention is paid to reliability, efficiency and user-friendly interface.

All controllers and software included in MIRTS meet the following requirements:

- support distributed governance structures;

- support popular network exchange protocols;

- have module versions for operation at temperatures up to $+55^{\circ} \mathrm{C}$ and in conditions of strong electromagnetic interference.

\section{Programmable logic controller}

Process control should ensure the highest possible economic efficiency of the equipment. More and more complex heat and power processes require an increase in the speed and reliability of technical means of automation. At the same time, the cost of rejection is growing. Progress in the field of automation tools is closely related to changes in the element base of computer technology. Now almost all devices are built on the basis of microprocessors. This allows processing more complex algorithms, increasing the accuracy of measuring technological parameters, and loading individual devices with functions that were previously not inherent to them. And, most importantly, exchange information with each other, working as a unified control system.

The technology used at TPS (actuators, regulatory bodies, information visualization tools, devices for documenting and archiving technological information) have undergone revolutionary changes in the second half of the last century thanks to the achievements of Soviet science [21]. The devices have become more compact, more reliable, more precisely, more technologically advanced in production. Modern actuators can receive commands in a digital code, decipher them, execute and report on their actions and their state. Control technology has gone from lamp regulators and relay-contact circuits to microprocessor-based regulating, logic and demonstration controllers.

The advantages of a PLC are:

- simple and convenient creation of technological programs;

- the ability to change the working control program without interfering with the system itself;

- simple and inexpensive maintenance;

- increased reliability at a reduced cost, in comparison with similar relay systems.

To write application programs, so-called technological languages are used. The International Electrotechnical Commission has developed the МЭК-61131-3 standard. The standard specifies 5 programming languages, most software systems make it possible to convert an already written program from one language to another. The most widely used languages are LAD, STL and FBD.

Some of the PLCs were used to develop an automated process control system for the combined cycle gas plant of the Dzerzhinsk TPS. Let's consider the main ones, make a comparison and justify the choice made.

Considering the complexity of industrial automation and the range of states of the controlled object, in the case of industrial facilities such as a TPS, we need large control systems under the control of SCADA systems. They are built on controllers that support medium and distributed automation.

In addition, industrial automation is hundreds and thousands of different signals, discrete and analog. So, only the boiler room of large thermal and hydroelectric power plants can include more than 5000 signals. Consequently, the ability of controllers to receive and process a large number of signals is required. This leads to the requirements for performance and speed, that is, the shortest possible data collection and processing cycle, 
high network bandwidth, fault tolerance and reliability. Also, the "power" of the controller concerns the amount of its memory, on which the complexity of the program it executes directly depends $[22,23]$.

Let's consider some controllers, namely Russian production, presented on the domestic market.

\section{The microcontrollers of the Russian production}

The Modern home-made controllers can differ in many parameters, but it is worth highlighting exactly those characteristics that distinguish a particular controller from others. Table 1 summarizes the technical characteristics of domestic controllers, which allows you to compare them.

Table 1. Microcontrollers characteristics

\begin{tabular}{|c|c|c|c|c|}
\hline Characteristics & TREI-5B & OWEN PLC210 & REGUL & MFC \\
\hline Processor type & $\begin{array}{l}\text { AMD Geode LX } \\
\text { PC104+ } \\
\text { with frequency of } \\
400 \mathrm{MHz}\end{array}$ & $\begin{array}{l}\text { ARM }{ }^{\circledR} \text { Cortex- } \\
\text { A8 } \\
\text { with frequency of } \\
800 \mathrm{MHz}\end{array}$ & \begin{tabular}{lrr} 
ARM & \multicolumn{2}{r}{ Cortex- } \\
Axx, 512 & Mb \\
RAM & &
\end{tabular} & $\begin{array}{l}\text { INTEL XScale® } \\
266 \text { or } 533 \mathrm{MHz}\end{array}$ \\
\hline Memory size & $\begin{array}{l}\text { RAM - } 1 \mathrm{MB} \\
\text { Flash disk from } \\
32 \mathrm{MB} \text { to } 2 \mathrm{~GB}\end{array}$ & $\begin{array}{l}\text { flash memory } \\
512 \mathrm{MB} \text { RAM - } \\
\text { 256 MB Retain } \\
\text { memory } 64 \mathrm{~KB}\end{array}$ & $\begin{array}{l}\text { The amount of } \\
\text { RAM } 2 \text { GB } \\
\text { ROM size } 4 \mathrm{~GB}\end{array}$ & $\begin{array}{l}64 \mathrm{Mb} \text { SDRAM, } \\
32 \mathrm{Mb} \text { Flash }\end{array}$ \\
\hline Interface & $\begin{array}{l}\text { RS-232/485, } \\
\text { Ethernet }\end{array}$ & $\begin{array}{l}\text { RS-232, RS-485, } \\
\text { Ethernet } 10 / 100\end{array}$ & $\begin{array}{l}\text { RS-422/RS-485, } \\
\text { Ethernet, USB }\end{array}$ & $\begin{array}{l}\text { Ethernet 100, } \\
\text { RS-485 }\end{array}$ \\
\hline Software & $\begin{array}{l}\text { Unimod PRO - } \\
\text { CASE-system for } \\
\text { programming } \\
\text { controllers, three } \\
\text { languages of } \\
\text { technological } \\
\text { programming in } \\
\text { accordance with } \\
\text { IEC 61131-3. }\end{array}$ & $\begin{array}{l}\text { Operating } \\
\text { system - } \\
\text { Linux, } \\
\text { Programming } \\
\text { languages IL, } \\
\text { ST, LD, SFC, } \\
\text { FBD + } \\
\text { additional } \\
\text { CFC } \\
\text { language }\end{array}$ & $\begin{array}{l}\text { Epsilon LD } \\
\text { runtime with } \\
\text { support for } 5 \text { IEC } \\
61131-3 \\
\text { languages. }\end{array}$ & $\begin{array}{l}\text { Epsilon LD } \\
\text { runtime with } \\
\text { support for } 5 \text { IEC } \\
61131-3 \\
\text { languages. }\end{array}$ \\
\hline $\begin{array}{l}\text { Number of } \\
\text { input-output } \\
\text { channels for } \\
\text { discrete and } \\
\text { analog signals }\end{array}$ & Up to 8169 & $\begin{array}{l}24 \text { discrete and } 4 \\
\text { analog channels }\end{array}$ & $\begin{array}{lr}\text { Discrete } & \text { input } \\
\text { module } & 16 \\
\text { channels, } & \text { analog } \\
\text { input } & - \\
\text { channels } & \\
\end{array}$ & $\begin{array}{lr}\text { Up to } & 976 \\
\text { analog, } & 256 \\
\text { discrete channels }\end{array}$ \\
\hline MTBF & 75000 hours & 60000 hours & $\begin{array}{l}\text { at least } 100,000 \\
\text { hours. }\end{array}$ & 130000 hours \\
\hline $\begin{array}{l}\text { Connectable } \\
\text { devices }\end{array}$ & $\begin{array}{l}\text { Keyboard, } \\
\text { monitor }\end{array}$ & USB stick & $\begin{array}{l}\text { connection of up } \\
\text { to } 255 \text { expansion } \\
\text { racks; } \\
\text { up to } 40 \text { modules } \\
\text { in one crate; } \\
\text { the possibility of } \\
\text { spacing the } \\
\text { subracks at a } \\
\text { distance of up to } \\
10 \mathrm{~km} \text { (via a } \\
\text { fiber-optic }\end{array}$ & $\begin{array}{l}13 \text { different types } \\
\text { of I / O modules } \\
\text { supporting all } \\
\text { major types of } \\
\text { sensors and } \\
\text { actuators }\end{array}$ \\
\hline
\end{tabular}




\begin{tabular}{|l|l|l|l|l|}
\hline Characteristics & TREI-5B & OWEN PLC210 & REGUL & MFC \\
\hline & & & $\begin{array}{l}\text { communication } \\
\text { line) }\end{array}$ & \\
\hline $\begin{array}{l}\text { Working } \\
\text { conditions }\end{array}$ & $-60^{\circ} \mathrm{C}$ to $+60^{\circ} \mathrm{C}$ & $-40^{0} \mathrm{C}$ to $+55^{\circ} \mathrm{C}$ & +1 to $+60^{\circ} \mathrm{C}$ & +1 to $+60^{\circ} \mathrm{C}$ \\
\hline $\begin{array}{l}\text { Galvanic } \\
\text { isolation }\end{array}$ & $1000 \mathrm{~V}$ to 2500 & Yes & $\begin{array}{l}\text { Channel-by- } \\
\text { channel or } \\
\text { general galvanic } \\
\text { isolation }\end{array}$ & $\begin{array}{l}\text { Double galvanic } \\
\text { isolation of } \\
\text { internal circuits } \\
\text { Controller from } \\
\text { input and } \\
\text { switching circuits } \\
\text { of signals 220 } \\
\text { VAC, 220 VDC }\end{array}$ \\
\hline Fastening & DIN rail & DIN rail & DIN rail & $\begin{array}{l}\text { The controller is } \\
\text { designed only for } \\
\text { horizontal } \\
\text { placement on the } \\
\text { mounting plane }\end{array}$ \\
\hline Dimensions & $100 \times 160 \mathrm{~mm}$ & $\begin{array}{l}(105 \times 124 \times 83) \pm 1 \\
\text { mm }\end{array}$ & $40 \times 180 \times 145 \mathrm{~mm}$ & \begin{tabular}{l}
$483 \times 265 \times 283$ \\
\hline
\end{tabular} \\
\hline
\end{tabular}

\section{An example of the automation of a waste heat boiler}

In 2019, at the Dzerzhinsk TPS, NVT-Systems designed an automated control system for an economizer boiler. Certain difficulties arose during the implementation of this system.First, this system had special requirements for reliability and redundancy. The second problem was the presence of other software and hardware complexes at the TPS, combined into a single system. The implemented software and hardware complex had to be integrated into the existing automation structure, in addition, to facilitate the work of technicians and engineers of the TPS, simplicity, reliability and redundancy were required.

The signals coming from the automation object are signals from pressure sensors, temperature sensors in liquid and gaseous media, liquid levels in the working volumes of the boiler unit. The actuators are drives of devices and valves. The purpose of the control is to ensure the normal functioning of the waste heat boiler and auxiliary equipment, taking into account all interlocks and protections.

The company "NVT-Systems" was required to develop a control system taking into account the specified conditions, the selection and supply of equipment and fittings, the implementation and delivery of the project in the form of control cabinets.

For the development of an automated control system, the above controllers could be used. The REGUL500 controller was chosen. Let us justify the choice made [24].

The controller is distinguished by very high performance and the speed of polling I / O modules. The controller can include several frames of modules of devices for connecting to the object, separated by distances of up to $10 \mathrm{~km}$ when using fiber-optic communication cables, which makes it possible to design distributed automated control systems. In addition to speed, reliability, ability to work in distributed systems in real time and popularity, the advantages of REGUL500 controllers are: high accuracy of measuring channels $-0.1 \%$ for signals of all types; the ability to hot-swap modules of all types; resistance to external influences (temperature, interference, etc.).

REGUL controllers support interfaces: RS-232 (9-pin, full duplex, speed 300-115 200 bps, opto-isolation 500/1500 V, overvoltage protection); RS-422 / RS-485 (9-pin, speed 300-115 200 bps, full channel-by-channel opto-isolation); Ethernet 10/100/1000 RJ-45 (full duplex) - up to 4 ports per CPU; Ethernet 10/100/1000 FO (Single-mode, Multi-mode) - up to 2 ports per CPU. 
The REGUL controller has a set of certificates, such as the certificate of conformity of the Customs Union, the certificate of conformity of the Eurasian Union, the certificate of conformity of the Federal Agency for Technical Regulation and Metrology, the certificate of conformity in the field of atomic energy use, compliance with the decree of the government of the Russian Federation No. 719 dated 17.07.2015. This makes it possible to use the REGUL controller for import substitution [12]. REGUL controllers support popular exchange protocols: Modbus RTU (Master / Slave), Modbus TCP (Master / Slave), OPC DA, OPC UA, EtherCAT, IEC 60870-5-101 (Master / Slave), IEC 60870-5-104 ( Master / Slave).

\section{Conclusions}

As mentioned above, when solving the automation problem, two tasks were especially acute - to provide increased reliability and redundancy, and also to combine the developed software and hardware complex with the existing ones. The hardware and software tools of the MIRTS platform successfully cope with these tasks, which provide the ability to connect to workstations and most controllers of a wide range of devices over networks with an electrical interface RS-485.

\section{References}

1. J. Rybak, Ch. Kongar-Syuryun, Y. Tyulyaeva, A. Khayrutdinov, I. Akinshin, Mining Science. 28.(2021). doi: 10.37190/msc212802

2. J. Rybak, S.M. Gorbatyuk, K.Ch. Bujanovna-Syuryun, A.M. Khairutdinov, Yu.S. Tyulyaeva, P.S. Makarov, Metallurgist 64 (2021). doi: 10.1007/s11015-021-01065-5;

3. Ch. Kongar-Syuryun, A. Ivannikov, Y. Tyulyaeva, A. Khayrutdinov, Materials Today: Proceedings. International Conference on Modern Trends in Manufacturing Technologies and Equipment (ICMTMTE). 6-10 September. 2021. Sevastopol, Russia, 38. doi: 10.1016/j.matpr.2020.10.145.

4. M.M. Khayrutdinov, Ch.B. Kongar-Syuryun, Yu.S. Tyulyaeva, A.M. Khayrutdinov, Bulletin of the Tomsk Polytechnic University. Geo Assets Engineering 331, 11 (2020). doi: 10.18799/24131830/2020/11/2883.

5. V.I. Golik, Ch.B. Kongar-Syuryun, Y.S. Tyulyaeva, A. Khayrutdinov, Bulletin of the Tula State University. Earth Science, 4. (2020).

6. Alexander Ivannikov, Andrey Chumakov, Vladimir Prischepov, Kristina Melekhina, Express determination of the grain size of nickel-containing minerals in ore material. Materials Today: Proceedings, 38 (2021).. https://doi.org/10.1016/j.matpr.2020.10.141

7. Ch. Kongar-Syuryun, A. Aleksakhin, A. Khayrutdinov, Y. Tyulyaeva, Materials Today: Proceedings. International Conference on Modern Trends in Manufacturing Technologies and Equipment (ICMTMTE). 6-10 September. Sevastopol, Russia, 38. (2021) doi: 10.1016/j.matpr.2020.10.139.

8. Goldobin Yu. M., Pavlyuk E. Yu., Automation of heat-power facilities (Yekaterinburg: Ural Federal University Press, 2017)

9. Pletnev, G. P. Automation of technological processes and production in heat and power engineering: [textbook for universities on the specialty " Automation of technological processes and production (power engineering)"] (Publishing house MPEI, 2007). 
10. Andyk V. S., Automated control systems for technological processes at TPP: textbook: (Moscow: Yurayt, 2017)

11. Volkova P. I., Dmitrieva V. V., GIAB, 6 (2011)

12. Sazhin S., Branch scientific and technical journal "ISUP", 6 (2010)

13. Grigoriev D. A., Vanhercke A.V., Galkin D. V., Environmentally-friendly and reliable automated control system of technological processes of a steam boiler. Branch scientific and technical journal "ISUP", 5 (2016)

14. Akhmedov N. Sh., Branch scientific and technical journal "ISUP", 2 (2008).

15. Automation of technological processes at a thermal power plant. http://pikzebra.ru>pub/ detail.php?ID=1844

16. Serezhkin V. S., GIAB, 6 (2011)

17. Melamed A. D., Chernousov N. Z., G. S., Reports of BSUIR, 6 (2015)

18. Popescu M., Mastorakis N., WSEAS Transaction on Systems, 3 (2010)

19. Mendelevich V. A., Automation and IT in power engineering, 7 (2015).

20. Mendelevich V. A., Automation and IT in power engineering, 2 (2020).

21. Grach V., Automation of the boiler room http://kotel.ru/avtomatika/avtomatizatsiyakotelnoj

22. Manas Kumar Parai, Banasree Das, Gautam Das. An Overview of Microcontroller Unit: from Proper Selection to Specific Application. International Journal of Soft Computing and Engineering (IJSCE) ISSN: 2231-2307, Volume-2 Issue-6, January 2013 PP 228-231

23. Yilmaz Güven, Sitki Kocooğlu, Ercan Cosgum, Harun Gezici. Understanding the Concept of Microcontroller Based Systems To Choose The Best Hardware for Applications. International Journal of Engineering And Science Vol.6, Issue 9 (September 2017), pp 38-44 Issn (e): 2278-4721, Issn (p):2319-6483, www.researchinventy.com

24. REGUL500 - controllers of domestic production for building distributed control systems. Moscow: Branch scientific and technical journal "ISUP" 2017, no. 2. 